\title{
Verb generation in children with spina bifida
}

\author{
MAUREEN DENNIS, $, 1,4,5$ DERRYN JEWELL, ${ }^{1}$ ROSS HETHERINGTON, $, 3,5$ CHRISTINE BURTON, ${ }^{5}$ \\ MICHAEL E. BRANDT, ${ }^{6}$ SUSAN E. BLASER, ${ }^{2}$ AND JACK M. FLETCHER ${ }^{7}$ \\ ${ }^{1}$ Program in Neurosciences \& Mental Health, The Hospital for Sick Children, Toronto, Ontario \\ ${ }^{2}$ Department of Radiology, The Hospital for Sick Children, Toronto, Ontario \\ ${ }^{3}$ AboutKidsHealth, The Hospital for Sick Children, Toronto, Ontario \\ ${ }^{4}$ Department of Surgery, University of Toronto, Toronto, Ontario \\ ${ }^{5}$ Department of Psychology, University of Toronto, Toronto, Ontario \\ ${ }^{6}$ Center for Computational Biomedicine, University of Texas Health Science Center at Houston, Houston, Texas \\ ${ }^{7}$ Department of Psychology, University of Houston, Houston, Texas
}

(Received May 18, 2007; Final Revision August 29, 2007; AccePted August 29, 2007)

\begin{abstract}
We investigated verb generation in children with spina bifida meningomyelocele ( $\mathrm{SBM} ; n=55)$ and in typically developing controls $(n=32)$. Participants completed 6 blocks ( 40 trials each) of a task requiring them to produce a semantically related verb in response to a target noun and an additional 40 trials on which they were simply required to read target nouns aloud. After controlling for reading response time, groups did not differ significantly in verb generation response time or learning. Children with SBM produced more non-verb errors than controls and tended to repeat their mistakes over blocks. Verb generation performance was associated with brain volume measures in participants with SBM. Congenital cerebellar dysmorphology is associated with impaired performance in verb generation accuracy, although not with increased response times to produce verbs.(JINS, 2008, 14, 181-191.)
\end{abstract}

Keywords: Cerebellum, Hydrocephalus, Meningomyelocele, Magnetic resonance imaging, Language, Verbal learning

\section{INTRODUCTION}

Recent evidence implicates the cerebellum in language processing and motor control of speech (Ackermann et al., 1999; Leggio et al., 2000). On a task requiring participants to generate a semantically related verb following a target noun, an adult with cerebellar damage showed failure to learn (i.e., no response speed decrements over trials), increased non-verb errors, and less error correction (Fiez et al., 1992). The seminal positron emission tomography (PET) studies of Petersen et al. (1989) showed right inferior lateral cerebellar activation during verb generation compared to a noun repetition condition, and other PET and functional magnetic resonance imaging (MRI) studies have found cerebellar activity during overt or covert verb generation tasks in both normal adults and children (Etard et al., 2000; Frings et al., 2006; Seger et al., 2000; Wood et al., 2004), with PET activation decreasing as responses become more automatized across trials (Raichle et al., 1994).

Correspondence and reprint requests to: Maureen Dennis, Ph.D., Program in Neurosciences \& Mental Health, Department of Psychology, The Hospital for Sick Children, 555 University Avenue, Toronto, ON, M5G 1X8, Canada. E-mail: maureen.dennis@ sickkids.ca
The cerebellum's role in verb generation, however, remains unclear. Some studies of patients with cerebellar damage caused by stroke, tumor, or atrophy report no learning deficits in this task (Helmuth et al., 1997; Richter et al., 2004). Patients with lateral cerebellar lesions also make more errors on antonym generation (Gebhart et al., 2002) and produce fewer responses on phonemic fluency tasks (Leggio et al., 2000) that, in controls, activate the cerebellum (Hubrich-Ungureanu et al., 2002). Verb generation and fluency are impaired after lesions to frontal, temporal, parietal, and striatal brain regions, particularly in the left hemisphere (Baxter \& Warrington, 1985; Hillis \& Caramazza, 1995; Hillis et al., 2002; Laiacona \& Caramazza, 2004; Miceli et al., 1984; Shapiro \& Caramazza, 2003). Patients with Parkinson's disease and dementia have difficulty with a verb fluency task, suggesting that the frontostriatal pathway is involved in verb production (Piatt et al., 1999). Specifically, the left frontal operculum, the left precentral gyrus, and anterior insula have been implicated in verb naming based on MRI on lesion patients (Tranel et al., 2001). Also, patients with hypoperfusion in the left posterior inferior frontal gyrus and precentral gyrus are impaired in written verb naming, an effect reversed by restoring blood flow 
(Hillis et al., 2003). In controls, Shapiro et al. (2001) implicated the left prefrontal cortex in verb production using repetitive transcranial magnetic stimulation and in a PET study, verb generation activated the left posterior middle and superior temporal gyri and Broca's area in the left inferior frontal lobe in addition to the right lateral cerebellum (Martin et al., 1995). Recent brain imaging work also supports a role for the frontal lobe, temporal lobe, and cingulate cortex (Booth et al., 1999; Bowyer et al., 2005; Burton et al., 2002; Grèzes \& Decety, 2001; Liégeois et al., 2004; Yee et al., 2000) in covert verb generation tasks.

The impact of congenital or childhood acquired cerebellar lesions is not well understood. Holland et al. (2001) reported that children use similar brain areas to adults during verb generation, but did not investigate the cerebellum. Children and adolescents with left-sided acquired cerebellar lesions responded more slowly on a verb generation task in response to pictures, but demonstrated the same degree of learning as controls or age peers with right-sided lesions (Richter et al., 2005). On another picture verb generation task, children aged 9-18 years with acute acquired cerebellar damage performed comparably to controls in terms of learning and errors, despite a slower response time (Frank et al., 2007).

Children with spina bifida meningomyelocele (SBM), a condition that typically involves congenital malformation of the cerebellum, offer a unique opportunity to study the developmental role of the cerebellum in language production using the verb generation task. SBM is the most common and severe form of spina bifida and the one of greatest interest regarding neuropsychological function because of its predictable pattern of brain abnormalities, including a cerebellum that is dysmorphic, herniated through the tentorial incisure and foramen magnum, and reduced in lateral cortex volume (Barkovich, 2000; Dennis et al., 2006a; Fletcher et al., 2005; Madsen et al., 2002). Compared to controls, however, individuals with SBM have similar or larger brain volumes in the medial cerebellum (Dennis et al., 2004; Edelstein et al., 2004) and enlarged cerebellar vermis linear measurements (Salman et al., 2006a). Other major brain dysmorphologies in this population include dysgenesis and hypoplasia of the corpus callosum, malformation of the midbrain, and thinning of the posterior cortex (Dennis et al., 2006a; Fletcher et al., 2004). The frontal cortex, by contrast, is thicker in the SBM brain than in controls (Juranek et al., 2007) and unlike the posterior cortex volume, is not dissociated by spinal lesion level (Fletcher et al., 2005).

Although any or all of these malformations may impair task performance, individuals with SBM demonstrate many deficits characteristic of cerebellar compromise, including impairments in balance and fine motor skills (Hetherington \& Dennis, 1999), short-duration timing (Dennis et al., 2004), and smooth pursuit eye movements (Salman et al., 2007), yet have intact motor learning (Colvin et al., 2003; Dennis et al., 2006b; Edelstein et al., 2004). They have speech deficits such as dysfluency, ataxic dysarthria, and slow speech rate (Huber-Okrainec et al., 2002) similar to those seen after acquired lesions of the cerebellum (Ackermann \& Hertrich, 2000; Brown et al., 1970; Darley et al., 1969a, 1969b; Huber et al., 2006, 2007; Riva \& Giorgi, 2000).

Verb generation performance in children with SBM is of some interest, given that their speech difficulties resemble those of individuals with other cerebellar compromise, that cerebellar malformation is a major dysmorphology of SBM, and that the cerebellum is implicated in verb generation. An important methodological procedure missing from many studies is a control for group differences in reading response time to ensure that differences in verb response time do not simply reflect slower reading processes. We studied verb generation in children with SBM, controlling for reading response times, and related verb generation to cerebellar and precallosal brain volumes (serving as proxies for frontal lobe volumes). The literature suggests slower and less accurate verb generation performance but intact learning, so we made the following predictions about children with $\mathrm{SBM}$, relative to age-matched controls.

1. Slower response time but intact learning, based on recent studies of motor learning in children with SBM (i.e., Colvin et al., 2003; Dennis et al., 2006b; Edelstein et al., 2004) and studies of verb generation in adults and children with cerebellar lesions (Frank et al., 2007; Helmuth et al., 1997; Richter et al., 2004, 2005).

2. More non-verb errors but intact error correction (given intact learning ability).

3. Fewer repeated verbs for different nouns within each block, based on Etard et al.'s (2000) notion that verbal rehearsal for generic verbs may involve the cerebellum. We expected more novel responses relating to each target noun in children with SBM, assuming they would correct initial errors over blocks.

\section{METHOD}

\section{Participants}

Eighty-seven individuals ranging in age from 8-19 years were studied at The Hospital for Sick Children in Toronto $(n=71)$ or the University of Texas Health Science CenterHouston $(n=16)$. The study met institutional ethics requirements for human research at each site and was conducted in accordance with the Helsinki Declaration. Participants gave informed assent or consent, and parents, informed consent. One group ( $n=55 ; 48$ from Toronto) had been diagnosed with SBM at birth and treated with a shunt shortly thereafter. Of those, 15 had no shunt revision, 18 had 1 revision, 13 had 2-4 revisions, and 9 had 5-9 revisions. Performance did not differ with respect to shunt revision history so participants with SBM were combined in the reported analyses. The other group comprised typically developing, age-matched controls ( $n=32 ; 23$ from Toronto), recruited through community advertisements, hospital newsletter 
advertisements, and word-of-mouth among staff at each testing facility.

Individuals with SBM have lesions at various levels of the spinal cord, with upper level lesions associated with greater cerebellar volume loss (Fletcher et al., 2005). Lesion level groups were combined after preliminary group comparisons revealed that participants performed similarly in terms of response error and response time regardless of whether they had an upper (thoracic-12 and higher; $n=15$ ) or lower (lumbar-1 and lower; $n=40$ ) spinal lesion level based on current taxonomies (Fletcher et al., 2005; Park et al., 1992).

All participants had IQ scores $\geq 70$ on either the Verbal Reasoning or Abstract/Visual Reasoning subtests of the Stanford-Binet Test of Intelligence-fourth edition (Thorndike et al., 1986) and scores above third grade on the LetterWord Identification subtest of the Woodcock-Johnson Psycho-Educational Battery-Revised (Woodcock \& Johnson, 1989). Exclusions (based on responses to parent questionnaires (SNAP-IV; Swanson, 1992), a diagnostic and statistical manual of mental disorders, fourth edition (American Psychiatric Association, 1994) based checklist for autism and pervasive developmental disorders, a medical history chart reviewed by a research nurse, and behavioral observations) were a diagnosis of neurological disorders unrelated to SBM, severe psychiatric disorder that precluded adequate cooperation (autism, psychosis, oppositional-defiant disorder), uncontrolled seizure disorder, or uncorrected sensory disorder.

Table 1 provides IQ and sociodemographic information. As expected, children with SBM had a lower IQ than controls, $t(83.63)=7.16, p<.001$. Differences in age, gender, ethnicity, and socioeconomic status were not statistically significant, $p>.05$. This study group involved children from previously reported studies of motor learning, attention orienting, and perceptual and motor timing (Dennis et al., 2004, 2005, 2006b; Edelstein et al., 2004).

Table 1. Demographic information for controls and participants with spina bifida meningomyelocele (SBM)

\begin{tabular}{lcc}
\hline \hline Group & $\begin{array}{c}\text { Controls } \\
(n=32)\end{array}$ & $\begin{array}{c}\text { SBM } \\
(n=55)\end{array}$ \\
\hline $\begin{array}{l}\text { Age (years; mean } \pm \text { standard deviation) } \\
\text { Gender }\end{array}$ & $13.11 \pm 2.38$ & $13.41 \pm 2.82$ \\
$\quad$ Male & $18(56.25)$ & $26(47.27)$ \\
$\quad$ Female & $14(43.75)$ & $29(52.73)$ \\
Ethnicity & & $50(90.91)$ \\
$\quad$ White & $24(75.00)$ & $0(.0)$ \\
Hispanic & $0(.0)$ & $3(5.45)$ \\
Asian & $5(15.63)$ & $0(.0)$ \\
$\quad$ African American & $2(6.25)$ & $2(3.64)$ \\
$\quad$ Other & $1(3.12)$ & $44.13 \pm 11.62$ \\
Socioeconomic Status* & $89.75 \pm 12.66$ & 14.17 \\
Stanford-Binet Composite IQ & $107.81 \pm 9.32$ & $89.75 \pm 1.96$ \\
\hline \hline
\end{tabular}

Note. Percentage listed in brackets after each frequency.

*Socioeconomic status was determined by the Hollingshead (1975) four factor scale.

\section{Brain Imaging Procedures}

\section{Participants}

Using structural MRI brain scans that were artifact-free, quantitative analysis of cerebellar volume was performed for 45 participants (21 children with lower lesions, 10 children with upper lesions, 14 controls) and of precallosal brain volume for 38 participants (12 children with lower lesions, 7 children with upper lesions, 19 controls). Cerebellar and precallosal data were available for 31 participants (11 children with lower lesions, 7 children with upper lesions, 13 controls), the discrepancies reflecting artifacts in either cerebrum or cerebellar acquisitions, but not both.

The participants providing the cerebellar volume data had a mean age of 13.10 years, $(S D=2.51)$, a mean IQ of $94.53(S D=15.92)$, and a mean socioeconomic score of $45.62(S D=13.11)$. Differences between the SBM and control groups in age, gender, ethnicity, and socioeconomic status were not statistically significant, $p>.05$, as in the larger sample. Participants with SBM scored lower than controls in IQ, $t(43)=4.36, p<.001$. Of the 31 participants with SBM, 5 had no shunt revision, 12 had 1 revision, 7 had 2-4 revisions, and 7 had 5-9 revisions.

The participants providing the precallosal brain volume data had a mean age of 13.19 years, $(S D=2.52)$, a mean IQ of $98.03(S D=14.78)$, and a mean socioeconomic score of $46.46(S D=11.82)$. Differences between the groups in age, gender, ethnicity, and socioeconomic status were not statistically significant, $p>.05$. Groups differed in IQ, with participants with SBM scoring lower than controls, $t(36)=$ $4.87, p<.001$. Of the 19 participants with SBM, 3 had no shunt revision, 7 had 1 revision, 5 had $2-4$ revisions, and 4 had 5-9 revisions.

\section{Image acquisition}

Imaging was completed at both testing sites (42 Toronto, 10 Houston) on comparable magnets (General Electric Signa, Milwaukee, WI) with the protocol standardized between sites and verified with phantom-scans. Three sets of images were acquired with external fiducial markers to co-register and position-normalize the scans. The initial series was a sagittal plane spin-echo T1-weighted localizer, FOV $24 \mathrm{~cm}$, TR $500 \mathrm{~ms}$, TE $14 \mathrm{~ms}, 256 \times 192$ matrix, $3 \mathrm{~mm}$ with a 0.3 skip, 2 repetitions. The localizer was followed by two whole brain coronal acquisitions. One series involved 3D fast spinecho T2-weighted images, FOV $24 \mathrm{~cm}$, TR $4000 \mathrm{~ms}$, TE $102 \mathrm{~ms}$, ETL 16, $256 \times 256$ matrix, and 1 repetition with contiguous $1.7 \mathrm{~mm}$ coronal images. The other series was a 3D-spoiled gradient-echo with contiguous $1.7 \mathrm{~mm}$ coronal images, FOV $24 \mathrm{~cm}$, TR $18 \mathrm{~ms}$, TE $3 \mathrm{~ms}$, Flip angle 25, 124 locations, $256 \times 256$ matrix, and 1 repetition. The T1-weighted scan volume, which provides superior whitegray contrast, was segmented separately to obtain white and gray matter tissue volumes. The T2-weighted scan was then clustered to extract cerebrospinal fluid (CSF) vol- 
umes, and the latter was used to adjust the white and gray matter volume measures obtained from the T1-weighted scan. The quantitative segmentation procedure is described in Dennis et al. (2004) and Fletcher et al. (2005) and in Appendix A.

\section{Verb generation task}

Participants sat approximately $50 \mathrm{~cm}$ from an IBMcompatible computer and wore a Shure Brothers headset with a microphone. As a pretest, participants read nouns presented on a screen ( 6 practice trials and 40 test trials). Response errors were not analyzed for this task because accuracy was at ceiling level. The median time was used as a covariate in the latency analyses to control for group differences in verbalization speed.

For the verb generation task, participants were told to "think of an action word that goes with each word. An action word describes something you could do to or with the word on the screen, or something the word on the screen could do by itself. When you think of an action word, say it out loud as quickly as you can." Participants also were told that they were permitted to repeat the same action word more than once. Each participant completed 10 practice trials and were reminded to say an action word if they produced non-verb responses. The test trials consisted of 6 blocks of 40 words, with each block having a different randomly ordered list of the same 40 words (see Appendix B). Participants were randomly assigned to a list order condition (i.e., 1, 2, 3, 4, 5, 6; 2, 3, 4, 5, 6, 1; 3, 4, 5, 6, 1, 2; etc.) by the computer.

Each word was presented in white typeface on a black screen with the rate determined by each participant's response latency. Following each response, a cross warned the participant to prepare for the next trial. Verbal responses were documented by the experimenter while the computer recorded the latency in milliseconds between word presentation and the microphone trigger following the participant response. If the microphone was accidentally triggered, or did not trigger when a response was given, the experimenter pressed a key to mark that trial as invalid, noted the invalid trial, and the next word was presented. All other trials were marked as valid by a key press. Stimulus words for trials that were marked invalid were re-presented at the end of that testing block. All blocks were audiotaped to ensure accurate response documentation.

\section{Data Analysis}

\section{Response time}

Median response times were calculated for correct responses for each participant for each block. Differences in median response times for the noun reading and verb generation tasks were explored with a $t$-test. Median response times for the verb generation task by block were entered into a repeated measure group means analysis, with response times for the noun reading task as a covariate. A separate analysis compared the effect of block order on response time. Response time data from one participant with SBM were excluded from the analyses because he was purposely trying to generate novel verbs during one block and thus, disregarding the instructions to produce a verb as fast as possible.

\section{Response errors}

Response errors over all blocks were categorized in relation to the target noun as: synonym, same generic category, superordinate, subordinate, whole-part relationship, associate, adjective, uninterpretable response, repeated stimuli, no response, multi-word response with a verb, and multi-word response without a verb. A non-parametric Mann-Whitney analysis explored differences between the participants with SBM and controls in total number of response errors. To compare the number of errors relative to the opportunity to make an error, each participant's total error score was divided by the total number of valid trials completed. To compare the number of different types of response errors relative to the total number of group errors, each participant's errors of each category were divided by the total number of errors for their group. The proportional error scores were entered into Mann-Whitney analyses to investigate differences between the groups. For error correction over blocks, percentage correct for each participant in each block was calculated and entered into Mann-Whitney analyses to compare group differences and separate Friedman repeated measures analyses were computed for the control and SBM groups to analyze performance over blocks.

\section{Response repetition}

To assess whether participants with SBM differed from controls in their tendency to repeat responses rather than generate a novel response, response repetition was analyzed in two ways. First, to assess response repetition across blocks (i.e., using the same verb to respond to a noun each time it was presented), the number of different responses (excluding derivatives and no responses) made by each participant was calculated separately for each of the 40 nouns over the 6 test blocks. The average number of responses across all words was entered into a Mann-Whitney analysis to compare group differences. Second, to assess response repetition within blocks (i.e., using the same generic verb to respond to several different nouns), the number of different responses (excluding derivatives and no responses) made by each participant was calculated for each of the 40 nouns within each of the 6 test blocks. The average number of responses across all blocks was entered into a $t$-test to explore potential group differences.

\section{Brain measures}

Precallosal and cerebellar brain volumes were compared across groups and whole volumes were correlated with verb generation performance by participants with SBM to explore potential brain-behavior relations. Data from one participant were excluded from the cerebellar correlational analy- 
ses because of extreme values (well below 2 standard deviations) on all cerebellar volume measures.

\section{RESULTS}

\section{Response Time}

Median response times for the noun reading task were analyzed by a $t$-test for samples with heterogeneous variance. Participants with SBM $(M=671.05, S D=215.37)$ were significantly slower than controls $(M=557.80, S D=77.71)$ in noun reading time, $t(72.84)=3.50, p<.005$.

A preliminary $t$-test analysis established whether verb generation response times were slower in individuals with SBM. Participants with SBM $(M=1854.50, S D=702.40)$ tended to respond more slowly than controls $(M=1566.75, S D=$ 685.68) but this difference did not meet the critical level of alpha (.05) adopted for this study, $t(84)=1.85, p=.067$.

Median response time values then were entered into a repeated measures analysis with the within-subject factor Block (1-6), the between-subject factor Group (SBM, control), and noun reading median response time as a covariate. The effect of Group was not significant, $F(1,83)=$ $1.17, p>.05$, nor was its interaction with Block with a Greenhouse-Geisser correction applied for violation of sphericity, $F(3.84,318.44)=1.02, p>.05$. The main effect of Block was significant, $F(3.84,318.44)=4.64, p<.005$, as was the interaction of Block and the noun reading time covariate, $F(3.84,318.44)=5.37, p<.001$. Participants generally improved their performance over time, showing the slowest performance in block $1(M=1767.97, S D=$ 573.28) and the fastest in block $6(M=1657.37, S D=790.56)$. The interaction between Block and reading response time was such that performance improved the most from block 1 to block 6 (measured by a difference between these scores) for the group with the slowest reading response time, $r_{s}(84)=$ $.28, p<.05$. Thus, individuals with a slower reading response time showed more of a block effect, although this did not translate into a difference between the groups.

The effect of list order on median response time was analyzed by a repeated measures analysis with the betweensubject factor Order (1-6), the within-subject factor Block (1-6), and median response time on the noun reading task as a covariate. Similar results as in the primary analysis were obtained for the effect of Block and its interaction with the covariate, but there was no significant effect of Order, $F(5,79)=1.20, p>.05$, nor its interaction with block, $F(18.87,298.12)=1.12, p>.05$.

\section{Response Errors}

Participants with SBM made more response errors than controls, Mann-Whitney $U=656.50, p<.05$. The pattern of errors (see Table 2) suggests that participants in the SBM group responded with more adjectives than controls, although the total number of errors of each type was not compared statistically.
Table 2. Average number of response errors (and standard deviation) by category for controls and participants with spina bifida meningomyelocele (SBM)

\begin{tabular}{llc}
\hline \hline Type of error & \multicolumn{1}{c}{ Controls } & SBM \\
\hline Synonym & $0.16(.72)-4.1 \%$ & $0.07(.33)-0.6 \%$ \\
Same generic & $0.03(.18)-0.8 \%$ & $0.11(.81)-1.0 \%$ \\
Superordinate & $0.06(.35)-1.5 \%$ & $0.04(.19)-0.4 \%$ \\
Subordinate & $0.03(.18)-0.8 \%$ & $0.16(.74)-1.4 \%$ \\
Whole-part & $0.09(.53)-2.3 \%$ & $0.25(.99)-2.2 \%$ \\
Associate & $1.09(2.45)-27.9 \%$ & $2.95(5.87)-26.0 \%$ \\
Adjective & $1.63(4.86)-41.7 \%$ & $6.27(18.10)-55.2 \%$ \\
Uninterpretable & $0.50(1.27)-12.8 \%$ & $1.07(2.17)-9.4 \%$ \\
Repeated noun & $0.16(.45)-4.1 \%$ & $0.13(.51)-1.1 \%$ \\
No response & $0.03(.18)-0.8 \%$ & $0.11(.57)-1.0 \%$ \\
Multi-word (with verb) & $0.06(.25)-1.5 \%$ & $0.16(.69)-1.4 \%$ \\
Multi-word (without verb) & $0.06(.25)-1.5 \%$ & $0.04(.19)-0.4 \%$ \\
Total & $3.91(8.07)$ & $11.36(23.36)$ \\
\hline \hline
\end{tabular}

Participants with SBM $(M=4.74 \%, S D=9.76)$ had a higher proportion of total errors relative to the total number of valid trials completed than controls $(M=1.63 \%, S D=$ 3.37), Mann-Whitney $U=655.00, p<.05$. However, participants with SBM did not differ from controls in the number of errors within each error category relative to the total number of errors made by each group (625 and 125 for the SBM and control groups, respectively), $p>05$.

Groups did not differ in the percentage of correct responses for the first block of verb generation trials, Mann-Whitney $U=732.00, p>.05$. However, group differences in accuracy on the third and fifth blocks attained significance, MannWhitney $U=673.50, p<.05$; Mann-Whitney $U=647.00$, $p<.05$, and differences approached significance on the second, fourth, and sixth blocks, $p \leq .06$. Additionally, separate Friedman tests revealed an effect of block for the control group, $\chi^{2}(5)=14.68, p<.05$, but not the SBM group, $\chi^{2}(5)=7.34, p>.05$. These results, illustrated by the block means displayed in Figure 1, are compatible with the notion that controls made more gains in error correction than participants with SBM.

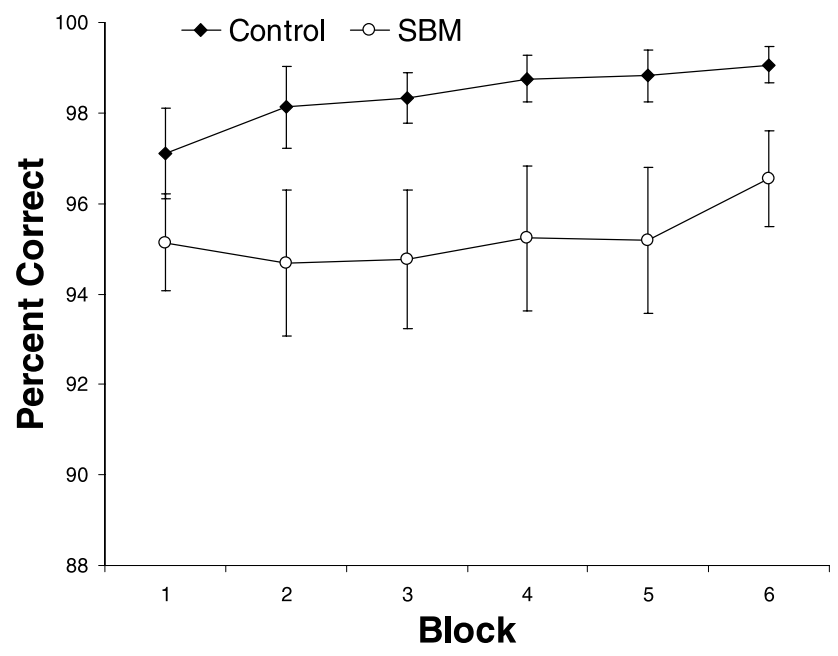

Fig. 1. Average percent correct for each block of the verb generation task for participants with SBM and controls. 
Table 3. Cerebellar volumes $\left(\mathrm{cm}^{3}\right)$ by region and tissue type in children with spina bifida meningomyelocele $(\mathrm{SBM} ; n=31)$ and in typically developing controls $(n=14)$

\begin{tabular}{lllccc}
\hline \hline Region & Group & CSF $M(S D)$ & Gray $M(S D)$ & White $M(S D)$ & Total $M(S D)$ \\
\hline Medial & Control & $2.68(.98)$ & $14.03(1.99)$ & $2.79(.77)$ & $19.50(3.04)$ \\
& SBM & $1.41(.70)^{*}$ & $14.35(4.02)$ & $3.36(1.31)$ & $19.13(5.10)$ \\
Lateral-left & Control & $1.99(.72)$ & $46.01(4.62)$ & $18.53(2.77)$ & $66.54(5.70)$ \\
Lateral-right & SBM & $1.72(.57)$ & $32.63(9.89)^{*}$ & $13.91(4.20)^{*}$ & $48.26(13.15)$ \\
& Control & $1.72(.53)$ & $49.84(5.18)$ & $14.76(1.60)$ & $66.32(5.83)$ \\
Whole & SBM & $1.66(.61)$ & $34.70(9.22)^{*}$ & $11.23(2.69)^{*}$ & $47.60(11.97)$ \\
& Control & $6.39(1.71)$ & $109.87(11.04)$ & $36.10(4.36)$ & $152.36(13.76)$ \\
& SBM & $4.79(1.64)$ & $81.67(22.22)$ & $28.52(7.46)$ & $114.99(29.14)$ \\
\hline
\end{tabular}

*Controls significantly different from SBM group, $p<.006$

\section{Response Repetition}

Groups did not differ in terms of response repetition across blocks; participants with SBM used the same response at each presentation of a noun to the same extent as controls, Mann-Whitney $U=791.50, p>.05$. Nor did groups differ in terms of response repetition within blocks; participants with SBM used a generic verb response for several different nouns to the same extent as controls, $t(85)=.60, p>.05$.

\section{Cerebellar and Precallosal Brain Volumes}

Table 3 shows measures of cerebellar volume by region and tissue type. Regional differences in cerebellar volumes were compared using Group (SBM, control) by Region (medial, lateral-left hemisphere, lateral-right hemisphere) by Tissue Type (CSF, gray, white) repeated measures ANOVA. Groups differed in overall cerebellar volume, $F(1,43)=20.73, p<.001$, but this effect was not explored because of the presence of a significant Greenhouse-Geissercorrected three-way interaction, $F(2.50,107.58)=41.78$, $p<.001$, indicating that the differences between the groups were not simply overall volume reductions, but instead reflected a different pattern of tissue type organization. Because of the violation of the sphericity assumption, $t$-tests appropriate for independent samples with a Bonferroni correction $(p<.006)$ were used to compare differences between the groups. As is displayed in Table 3, the SBM group had a significantly smaller volume of medial region CSF compared to controls, as well as smaller white and gray matter volumes in both the lateral left and right cerebellar hemispheres.

Measures of precallosal volume by hemisphere and tissue type are given in Table 4. Differences in precallosal brain volumes were compared using Group (SBM, control) by Hemisphere (right, left) by Tissue Type (CSF, gray, white) repeated measures ANOVA. Groups differed in overall precallosal volume, $F(1,36)=26.85, p<.001$, but the Greenhouse-Geisser-corrected Group by Tissue Type interaction was significant as well, $F(1.17,42.06)=15.32, p<$ .001 . Post hoc $t$-tests, performed with a Bonferroni correction $(p<.006)$ because of a violation of the sphericity assumption, confirmed that participants with SBM had a larger precallosal volume of all three types of tissue. The interaction of Hemisphere and Tissue Type was also significant, $F(1.58,56.69)=11.43, p<.001$, when corrected for a violation of the sphericity assumption. Post hoc exploration of this interaction by paired $t$-tests with a Bonferroni correction $(p<.006)$ indicated that white matter volume was greater in the right hemisphere than the left for all participants combined, whereas the gray matter and CSF volumes were comparable across hemispheres. Larger precallosal volumes in SBM participants were not simply because of larger total cerebral volumes than controls in general, $t(36)=1.62, p>.05$.

Table 4. Precallosal cerebral volumes $\left(\mathrm{cm}^{3}\right)$ by hemisphere and tissue type in children with spina bifida meningomyelocele (SBM; $n=19)$ and in typically developing controls $(n=19)$

\begin{tabular}{llcccr}
\hline \hline Region & Group & CSF $M(S D)$ & Gray $M(S D)$ & White $M(S D)$ & Total $M(S D)$ \\
\hline Left & Control & $3.02(1.06)$ & $56.72(7.96)$ & $20.27(3.19)$ & $80.01(10.86)$ \\
& SBM & $6.33(3.49)$ & $75.88(16.07)$ & $27.74(6.52)$ & $109.95(23.13)$ \\
Right & Control & $3.29(1.21)$ & $56.73(7.72)$ & $22.32(3.56)$ & $82.35(11.37)$ \\
& SBM & $6.85(3.47)$ & $76.27(17.11)$ & $31.20(6.96)$ & $114.31(25.06)$ \\
\multirow{2}{*}{ Whole } & Control & $6.31(2.23)$ & $113.45(15.41)$ & $42.59(6.47)$ & $162.36(21.84)$ \\
& SBM & $13.18(6.64)^{*}$ & $152.14(32.63)^{*}$ & $58.94(13.15)^{*}$ & $224.26(47.27)$ \\
\hline \hline
\end{tabular}

*Controls significantly different from SBM group, $p<.006$ 


\section{Brain-Behavior Correlations}

Partial correlations controlling for age and relating the individual cerebellar and precallosal volumetric data with learning (difference in median response time on the first and sixth block), average median response time across blocks on the verb generation task, and median response time on the noun reading task were calculated for the SBM group only. None of these correlations was significant, $p>.05$.

Spearman correlations were calculated for total number of associate and adjective type errors and total number of overall errors with cerebellar and precallosal volumetric measures for the SBM group only. In these participants, number of associate errors correlated negatively with precallosal white volume, $r_{s}(17)=-.50, p<.05$, and cerebellar white volume, $r_{s}(28)=-.39, p<.05$, such that increased errors were associated with smaller brain volumes.

\section{DISCUSSION}

Children with SBM were less accurate and tended to be slower than controls to generate verbs. Whereas the accuracy was specific to verbs, the response time reflected a more general slowing in reading time. They demonstrated intact learning, responding faster with repeated exposure to the task, although they did not correct response errors and repeated roughly the same number of responses as controls within and across blocks. They differed from controls in terms of cerebellar and precallosal brain volumes and their brain volumes correlated with verb generation errors.

The data bear on several issues, including the methodology of group comparisons in verb generation tasks; verb generation performance in children with congenital cerebellar dysmporphology; child versus adult verb generation data; and the putative brain bases of verb generation.

Clinical groups often differ in fundamental response time for basic reading processes. We established whether reading response time differences drove group response time differences in verb generation, finding that children with SBM and control groups were equally rapid in producing accurate verbs to nouns once reading response time was controlled.

That children with SBM were able to learn through repetition and decrease their response time is consistent with reports of their successful learning in a variety of paradigms (e.g., Dennis et al., 2006b; Edelstein et al., 2004; Salman et al., 2006b). Repeated exposure to the same task allows children with SBM to improve their response time on the verb generation task, a form of learning more similar to adaptive and sequence motor learning tasks than to complex verbal learning tasks on which they are impaired (Yeates et al., 1995).

The cerebellum may be involved in general response search processes and the frontal region with response selection (Desmond et al., 1998; Marvel et al., 2004), both components of the verb generation task. Children with hydrocephalus, many with SBM, have impaired word finding, taking longer to name a target based on semantic cues, and difficulty with rapid naming (Dennis et al., 1987). Assuming participants with SBM in this study had generic difficulty generating responses, they may not have even reached the stage of evaluating whether the word was a verb and selecting it over a noun alternative. However, the fact that their errors were related words rather than nonresponses indicates that they were better able to find an associated word than to determine its appropriateness for the target.

The cerebellum is also involved in error detection and correction on motor tasks and might perform an analogous role on cognitive tasks (Ito, 1997; Thach, 1997). Patients with cerebellar compromise may make more non-verb errors because they cannot detect response suitability (Marvel et al., 2004) or correct errors on subsequent trials. Children with hydrocephalus, most with SBM, have demonstrated difficulties in error monitoring of anomalies in meaning and syntactic structure (Dennis et al., 1987). Their spontaneous speech is more tangential, less focused, and more verbose (Dennis et al., 1994). On the verb generation task, the tendency to verbalize associated but irrelevant concepts without monitoring their appropriateness may be related to a broader semantic deficit manifested in an inability to iteratively generate semantic coherence by monitoring, suppression, and revision processes (Barnes et al., 2007a, 2007b).

Age per se does not seem to be the main determinant of whether individuals with cerebellar compromise are impaired on verb generation performance. Recent studies of adults and children with acquired cerebellar damage report that verb generation learning and/or accuracy generally are not affected despite a slower response time (Frank et al., 2007; Helmuth et al., 1997; Richter et al., 2004, 2005). Our study of congenital cerebellar compromise reveals similar results with respect to learning and response time (without covarying for reading response time) but highlights impairments in accuracy and suggests difficulties with error monitoring. Learning remains intact whether the damage is congenital or acquired in childhood or adult life. In contrast, verb generation accuracy varies with whether the cerebellar insult is congenital or acquired. What remains to be explored are issues of extent of damage and prior experience.

Although children with SBM had a decreased cerebellar brain volume, their precallosal volume was actually larger than controls, the latter finding consistent with a recent MRI report on their frontal cortical thickness (Juranek et al., 2007). In our study, larger anterior white matter volumes correlated with fewer verb generation errors. That children, whose frontal lobes are not fully mature, might have disproportionate difficulty in generating verbs rather than nouns is consistent with the idea that frontal lobe damage impairs verb production (Daniele et al., 1994). Accordingly, the cerebellum is involved in verb production to the extent that it has close functional relations with the frontal lobe (Silveri \& Misciagna, 2000). However, the cerebellum itself might contribute to verb generation in children with SBM, who had fewer errors with larger cerebellar white matter volume. Although individuals with SBM have other major brain dysmorphologies that may play a part in verb gener- 
ation impairments, the cerebellum is well-positioned to contribute to language processing, being connected to subcortical and cortical language areas (Fabbro, 2000) such as Broca's area (Kim \& Thompson, 2000). Though exploratory, these correlations suggest that cerebellar and anterior region variability are determinants of performance in children with SBM, which is consistent with evidence that verb generation involves more anterior brain regions as well as the cerebellum (Bowyer et al., 2005; Burton et al., 2002; Etard et al., 2000; Grèzes \& Decety, 2001; Liégeois et al., 2004; Seger et al., 2000; Wood et al., 2004; Yee et al., 2000). Future studies of children with congenital cerebellar malformations should investigate the neural basis of how verbs are generated in real time.

\section{ACKNOWLEDGMENTS}

This work was funded by the National Institute of Child Health and Human Development Grant P01 HD35946 "Spina Bifida: Cognitive and Neurobiological Variability". No financial conflicts of interest exist with respect to this manuscript. The information in this manuscript and the manuscript itself is an original work that is not currently under review elsewhere and has not been previously published in any form.

The authors wish to thank Paul Cirino, Joanne Bosloy, Jennifer Janes, Andrea Martin, Amy Walker, Irene Townsend, Susan Inwood, Rebekah Nelson, Bravina Bala, Gesine Alders, and Caitlin Mahy for research assistance, and three anonymous reviewers for their insightful comments and suggestions.

\section{REFERENCES}

Ackermann, H., Gräber, S., Hertrich, I., \& Daum, I. (1999). Phonemic vowel length contrasts in cerebellar disorders. Brain and Language, 67, 95-109.

Ackermann, H. \& Hertrich, I. (2000). The contribution of the cerebellum to speech processing. Journal of Neurolinguistics, 13, 95-116.

American Psychiatric Association. (1994). Diagnostic and statistical manual of mental disorders (4th ed.). Washington, DC: American Psychiatric Publishing.

Barkovich, A.J. (2000). Pediatric neuroimaging (3rd ed.). Philadelphia, PA: Lippincott Williams \& Wilkins.

Barnes, M.A., Huber, J., Johnston, A.M., \& Dennis, M. (2007a). A model of comprehension in spina bifida meningomyelocele: Meaning activation, integration, and revision. Journal of the International Neuropsychological Society, 13, 854-864.

Barnes, M.A., Johnston, A.M., \& Dennis, M. (2007b). Comprehension in a neurodevelopmental disorder, spina bifida myelomeningocele. In K. Cain \& J. Oakhill (Eds.), Children's Comprehension Problems in Oral and Written Language: A Cognitive Perspective (pp. 193-217). New York: The Guilford Press.

Baxter, D.M. \& Warrington, E.K. (1985). Category specific phonological dysgraphia. Neuropsychologia, 23, 653-666.

Bensaid, A.M., Hall, L.O., Bezdek, J.C., Clarke, L.P., Silbiger, M.L., Arrington, J.A., \& Murtagh, R.F. (1996). Validity-guided (re)clustering with applications to image segmentation. IEEE Transactions on Fuzzy Systems, 4, 112-123.

Bezdek, J.C. (1981). Pattern Recognition with Fuzzy Objective Function Algorithms. New York: Plenum Press.
Bezdek, J.C. \& Pal, S.K. (1992). Fuzzy Models for Pattern Recognition: Methods that Search for Structures in Data. New York: Institute of Electrical and Electronics Engineers.

Booth, J.R., Macwhinney, B., Thulborn, K.R., Sacco, K., Voyvodic, J., \& Feldman, H.M. (1999). Functional organization of activation patterns in children: Whole brain $\mathrm{fMRI}$ imaging during three different cognitive tasks. Progress in Neuro-Psychopharmacology \& Biological Psychiatry, 23, 669-682.

Bowyer, S.M., Fleming, T., Greenwald, M.L., Moran, J.E., Mason, K.M., Weiland, B.J., Smith, B.J., Barkley, G.L., \& Tepley, N. (2005). Magnetoencephalographic localization of the basal temporal language area. Epilepsy \& Behavior, 6, 229-234.

Brandt, M.E. (1995). Method and apparatus for estimating tissue volumes in magnetic resonance images. U.S. Patent No. 5,425,368. Washington, DC: US Patent and Trademark Office.

Brandt, M.E., Bohan, T.P., Kramer, L.A., \& Fletcher, J.M. (1994). Estimation of CSF, white and gray matter volumes in hydrocephalic children using fuzzy clustering of MR images. Computerized Medical Imaging and Graphics, 18, 25-34.

Brandt, M.E., Bohan, T.P., Thorstad, K., McCauley, S.R., Davidson, K.C., Francis, D.J., Kramer, L.A., \& Fletcher, J.M. (1996). Reliability of brain structure morphometry in hydrocephalic children using MR images. Magnetic Resonance Imaging, 14, 649-655.

Brandt, M.E., Fletcher, J.M., \& Bohan, T.P. (1992). Estimation of CSF, white, and gray matter volumes from MRIs of hydrocephalic and HIV-positive subjects. Proceedings of SimTec/ WNN, 643-650.

Brown, J.R., Darley, F.L., \& Aronson, A.E. (1970). Ataxic dysarthria. International Journal of Neurology, 7, 302-318.

Burton, H., Snyder, A.Z., Diamond, J.B., \& Raichle, M.E. (2002). Adaptive changes in early and late blind: A fMRI study of verb generation to heard nouns. Journal of Neurophysiology, 88, 3359-3371.

Colvin, A.N., Yeates, K.O., Enrile, B.G., \& Coury, D.L. (2003). Motor adaptation in children with myelomeningocele: Comparison to children with ADHD and healthy siblings. Journal of the International Neuropsychological Society, 9, 642-652.

Daniele, A., Giustolisi, L., Silveri, M.C., Colosimo, C., \& Gainotti, G. (1994). Evidence for a possible neuroanatomical basis for lexical processing of nouns and verbs. Neuropsychologia, $32,1325-1341$.

Darley, F.L., Aronson, A.E., \& Brown, J.R. (1969a). Differential diagnostic patterns of dysarthria. Journal of Speech and Hearing Research, 12, 246-269.

Darley, F.L., Aronson, A.E., \& Brown, J.R. (1969b). Clusters of deviant speech dimensions in the dysarthrias. Journal of Speech and Hearing Research, 12, 462-496.

Dennis, M., Edelstein, K., Copeland, K., Frederick, J., Francis, D.J., Hetherington, R., Blaser, S.E., Kramer, L.A., Drake, J.M., Brandt, M.E., \& Fletcher, J.M. (2005). Covert orienting to exogenous and endogenous cues in children with spina bifida. Neuropsychologia, 43, 976-987.

Dennis, M., Edelstein, K., Hetherington, R., Copeland, K., Frederick, J., Blaser, S.E., Kramer, L.A., Drake, J.M., Brandt, M., \& Fletcher, J.M. (2004). Neurobiology of perceptual and motor timing in children with spina bifida in relation to cerebellar volume. Brain, 127, 1292-1301.

Dennis, M., Hendrick, E.B., Hoffman, H.J., \& Humphreys, R.P. (1987). Language of hydrocephalic children and adolescents. Journal of Clinical and Experimental Neuropsychology, 9, 593-621. 
Dennis, M., Jacennik, B., \& Barnes, M.A. (1994). The content of narrative discourse in children and adolescents after earlyonset hydrocephalus and in normally developing age peers. Brain \& Language, 46, 129-165.

Dennis, M., Jewell, D., Edelstein, K., Brandt, M.E., Hetherington, R., Blaser, S.E., \& Fletcher, J.M. (2006b). Motor learning in children with spina bifida: Intact learning and performance on a ballistic task. Journal of the International Neuropsychological Society, 12, 598-608.

Dennis, M., Landry, S.H., Barnes, M., \& Fletcher, J.M. (2006a). A model of neurocognitive function in spina bifida over the life span. Journal of the International Neuropsychological Society, 12, 285-296.

Desmond, J.E., Gabrieli, J.D.E., \& Glover, G.H. (1998). Dissociation of frontal and cerebellar activity in a cognitive task: Evidence for a distinction between selection and search. NeuroImage, 7, 368-376.

Edelstein, K., Dennis, M., Copeland, K., Frederick, J., Francis, D., Hetherington, R., Brandt, M.E., \& Fletcher, J.M. (2004). Motor learning in children with spina bifida: Dissociation between performance level and acquisition rate. Journal of the International Neuropsychological Society, 10, 877-887.

Etard, O., Mellet, E., Papathanassiou, D., Benali, K., Houdé, O., Mazoyer, B., \& Tzourio-Mazoyer, N. (2000). Picture naming without Broca's and Wernicke's area. NeuroReport, 11, 617-622.

Fabbro, F. (2000). Introduction to language and cerebellum. Journal of Neurolinguistics, 13, 83-94.

Fiez, J.A., Petersen, S.E., Cheney, M.K., \& Raichle, M.E. (1992). Impaired non-motor learning and error detection associated with cerebellar damage: A single case study. Brain, 115, $155-178$.

Filipek, P.A., Richelme, C., Kennedy, D.N., Rademacher, J., Pitcher, D.A., Zidel, S., \& Caviness, S. (1992). Morphometric analysis of the brain in developmental language disorders and autism. Annals of Neurology, 32, 475.

Fletcher, J.M., Bohan, T.P., Brandt, M.E., Brookshire, B.L., Beaver, S., Francis, D.J., Davidson, K., Thompson, N., \& Miner, M. (1992). Cerebral white matter and cognition in hydrocephalic children. Archives of Neurology, 49, 818-824.

Fletcher, J.M., Copeland, K., Frederick, J.A., Blaser, S.E., Kramer, L.A., Northrup, H., Hannay, H.J., Brandt, M.E., Francis, D.J., Villarreal, G., Drake, J.M., Laurent, J.P., Townsend, I., Inwood, S., Boudousquie, A., \& Dennis, M. (2005). Spinal lesion level in spina bifida: A source of neural and cognitive heterogeneity. Journal of Neurosurgery: Pediatrics, 102, 268-279.

Fletcher, J.M., Dennis, M., Northrup, H., Barnes, M.A., Hannay, H.J., Landry, S.H., Copeland, K., Blaser, S.E., Kramer, L.A., Brandt, M.E., \& Francis, D.J. (2004). Spina bifida: Genes, brain, and development. International Review of Research in Mental Retardation, 29, 63-117.

Fletcher, J.M., McCauley, S.R., Brandt, M.E., Bohan, T.P., Kramer, L.A., Francis, D.J., Thorstad, K., \& Brookshire, B.L. (1996). Regional brain tissue composition in children with hydrocephalus: Relationships with cognitive development. Archives of Neurology, 53, 549-557.

Frank, B., Schoch, B., Hein-Kropp, C., Dimitrova, A., Hövel., M., Ziegler, W., Gizewski, E.R., \& Timmann, D. (2007). Verb generation in children and adolescents with acute cerebellar lesions. Neuropsychologia, 45, 977-988.

Frings, M., Dimitrova, A., Schorn, C.F., Elles, H.-G., Hein-Kropp, C., Gizewski, E.R., Diener, H.C., \& Timmann, D. (2006). Cerebellar involvement in verb generation: An fMRI study. Neuroscience Letters, 409, 19-23.
Gebhart, A.L., Petersen, S.E., \& Thach, W.T. (2002). Role of the posterolateral cerebellum in language. Annals of the New York Academy of Sciences, 978, 318-333.

Gerig, G., Kubler, O., Kikinis, R., \& Jolesz, F.A. (1992). Nonlinear anisotropic filtering of MRI data. IEEE Transactions on Medical Imaging, 11, 221-232.

Grèzes, J. \& Decety, J. (2001). Functional anatomy of execution, mental simulation, observation, and verb generation of actions: A meta-analysis. Human Brain Mapping, 12, 1-19.

Helmuth, L.L., Ivry, R.B., \& Shimizu, N. (1997). Preserved performance by cerebellar patients on tests of word generation, discrimination learning, and attention. Learning \& Memory, 3, 456-474.

Hetherington, R. \& Dennis, M. (1999). Motor function profile in children with early onset hydrocephalus. Developmental Neuropsychology, 15, 25-51.

Hillis, A.E. \& Caramazza, A. (1995). Representation of grammatical categories of words in the brain. Journal of Cognitive Neuroscience, 7, 396-407.

Hillis, A.E., Tuffiash, E., \& Caramazza, A. (2002). Modalityspecific deterioration in naming verbs in nonfluent primary progressive aphasia. Journal of Cognitive Neuroscience, 14, 1099-1108.

Hillis, A.E., Wityk, R.J., Barker, P.B., \& Caramazza, A. (2003). Neural regions essential for writing verbs. Nature Neuroscience, 6, 19-20.

Holland, S.K., Plante, E., Weber Byars, A., Strawsburg, R.H., Schmithorst, V.J., \& Ball, W.S., Jr. (2001). Normal fMRI brain activation patterns in children performing a verb generation task. NeuroImage, 14, 837-843.

Hollingshead, A.B. (1975). The four factor index of social status. Unpublished manuscript, Yale University, New Haven, CT.

Huber, J.F., Bradley, K., Spiegler, B.J., \& Dennis, M. (2006). Longterm effects of transient cerebellar mutism after cerebellar astrocytoma or medulloblastoma tumor resection in childhood. Child's Nervous System, 22, 132-138.

Huber, J.F., Bradley, K., Spiegler, B., \& Dennis, M. (2007). Longterm neuromotor speech deficits in survivors of childhood posterior fossa tumors: Effects of tumor type, radiation, age at diagnosis, and survival years. Journal of Child Neurology, 22, 848-854.

Huber-Okrainec, J., Dennis, M., Brettschneider, J., \& Spiegler, B.J. (2002). Neuromotor speech deficits in children and adults with spina bifida and hydrocephalus. Brain and Language, 80, 592-602.

Hubrich-Ungureanu, P., Kaemmerer, N., Henn, F.A., \& Braus, D.F. (2002). Lateralized organization of the cerebellum in a silent verbal fluency task: A functional magnetic resonance imaging study in healthy volunteers. Neuroscience Letters, 319 , 91-94.

Ito, M. (1997). Cerebellar microcomplexes. International Review of Neurobiology, 41, 475-487.

Juranek, J.J., Castillo, E.M., Alvarez, P.P., Ewing-Cobbs, L., Sarkari, S., \& Papanicolaou, A.C. (2007). Anatomical and functional differences in children with spina bifida: MRI and MEG studies. Paper presented at the meeting of the International Neuropsychological Society, Bilbao, Spain.

Kim, M. \& Thompson, C.K. (2000). Patterns of comprehension and production of nouns and verbs in agrammatism: Implications for lexical organization. Brain and Language, 74, 1-25.

Laiacona, M. \& Caramazza, A. (2004). The noun/verb dissociation in language production: Varieties of causes. Cognitive Neuropsychology, 21, 103-123. 
Leggio, M.G., Silveri, M.C., Petrosini, L., \& Molinari, M. (2000). Phonological grouping is specifically affected in cerebellar patients: A verbal fluency study. Journal of Neurology, Neurosurgery and Psychiatry, 69, 102-106.

Liégeois, F., Connelly, A., Cross, J.H., Boyd, S.G., Gadian, D.G., Vargha-Khadem, F., \& Baldeweg, T. (2004). Language reorganization in children with early-onset lesions of the left hemisphere: An fMRI study. Brain, 127, 1229-1236.

Madsen, J.R., Young Poussaint, T., \& Barnes, P.D. (2002). Congenital malformations of the cerebellum and posterior fossa. In M.-U. Manto \& M. Pandolfo (Eds.), The cerebellum and its disorders (pp. 161-177). Cambridge: Cambridge University Press.

Martin, A., Haxby, J.V., Lalonde, F.M., Wiggs, C.L., \& Ungerleider, L.G. (1995). Discrete cortical regions associated with knowledge of color and knowledge of action. Science, 270, 102-105.

Marvel, C.L., Schwartz, B.L., \& Isaacs, K.L. (2004). Word production deficits in schizophrenia. Brain and Language, 89, 182-191.

Miceli, G., Silveri, M.C., Villa, G., \& Caramazza, A. (1984). On the basis for the agrammatic's difficulty in producing main verbs. Cortex, 20, 207-220.

Pao, Y.-H. (1989). Adaptive pattern recognition and neural networks. Reading, MA: Addison-Wesley.

Park, C.H., Stewart, W., Khoury, M.J., \& Mulinare, J. (1992). Is there etiologic heterogeneity between upper and lower neural tube defects? American Journal of Epidemiology, 136, 1493-1501.

Petersen, S.E., Fox, P.T., Posner, M.I., Mintun, M., \& Raichle, M.E. (1989). Positron emission tomographic studies of the processing of single words. Journal of Cognitive Neuroscience, 1 , 153-170.

Piatt, A.L., Fields, J.A., Paolo, A.M., Koller, W.C., \& Tröster, A.I. (1999). Lexical, semantic, and action verbal fluency in Parkinson's disease with and without dementia. Journal of Clinical and Experimental Neuropsychology, 21, 435-443.

Raichle, M.E., Fiez, J.A., Videen, T.O., Macleod, A.-M.K., Pardo, J.V., Fox, P.T., \& Petersen, S.E. (1994). Practice-related changes in human brain functional anatomy during nonmotor learning, Cerebral Cortex, 4, 8-26.

Richter, S., Kaiser, O., Hein-Kropp, C., Dimitrova, A., Gizewski, E., Beck, A., Aurich, V., Ziegler, W., \& Timmann, D. (2004). Preserved verb generation in patients with cerebellar atrophy. Neuropsychologia, 42, 1235-1246.

Richter, S., Schoch, B., Kaiser, O., Groetschel, H., Hein-Kropp, C., Maschke, M., Dimitrova, A., Gizewski, E., Ziegler, W., Karnath, H.-O., \& Timmann, D. (2005). Children and adolescents with chronic cerebellar lesions show no clinically relevant signs of aphasia or neglect. Journal of Neurophysiology, 94, 4108-4120.
Riva, D. \& Giorgi, C. (2000). The cerebellum contributes to higher functions during development: Evidence from a series of children surgically treated for posterior fossa tumours. Brain, 123, 1051-1061.

Salman, M.S., Blaser, S.E., Sharpe, J.A., \& Dennis, M. (2006a). Cerebellar vermis morphology in children with spina bifida and Chiari type II malformation. Child's Nervous System, 22, 385-393.

Salman, M.S., Sharpe, J.A., Eizenman, M., Lillakas, L., To, T., Westall, C., Steinbach, M.J., \& Dennis, M. (2006b). Saccadic adaptation in Chiari type II malformation. Canadian Journal of Neurological Sciences, 33, 372-378.

Salman, M.S., Sharpe, J.A., Lillikas, L., Steinbach, M.J., \& Dennis, M. (2007). Smooth ocular pursuit in Chiari type II malformation. Developmental Medicine \& Child Neurology, 49, 289-293.

Seger, C.A., Desmond, J.E., Glover, G.H., \& Gabrieli, J.D.E. (2000). Functional magnetic resonance imaging evidence for righthemisphere involvement in processing unusual semantic relationships. Neuropsychology, 14, 361-369.

Shapiro, K. \& Caramazza, A. (2003). Looming a loom: Evidence for independent access to grammatical and phonological properties in verb retrieval. Journal of Neurolinguistics, 16, 85-111.

Shapiro, K.A., Pascual-Leone, A., Mottaghy, F.M., Gangitano, M., \& Caramazza, A. (2001). Grammatical distinctions in the left frontal cortex. Journal of Cognitive Neuroscience, 13, 713-720.

Silveri, M.C. \& Misciagna, S. (2000). Language, memory, and the cerebellum. Journal of Neurolinguistics, 13, 129-143.

Swanson, J.M. (1992). School-based assessments and interventions for students with ADHD. Irvine, CA: KC Press.

Thach, W.T. (1997). Context-response linkage. International Review of Neurobiology, 41, 599-611.

Thorndike, R.L., Hagen, E.P., \& Sattler, J.M. (1986). The StanfordBinet Intelligence Scale (4th ed.). Itasca, IL: Riverside.

Tranel, D., Adolphs, R., Damasio, H., \& Damasio, A.R. (2001). A neural basis for the retrieval of words for actions. Cognitive Neuropsychology, 18, 655-670.

Wood, A.G., Harvey, A.S., Wellard, R.M., Abbott, D.F., Anderson, V., Kean, M., Saling, M.M., \& Jackson, G.D. (2004). Language cortex activation in normal children. Neurology, 63, 1035-1044.

Woodcock, R.W. \& Johnson, M.B. (1989). Woodcock-Johnson Psycho-Educational Battery-Revised. Allen, TX: DLM Teaching Resources.

Yeates, K.O., Enrile, B.G., Loss, N., Blumenstein, E., \& Delis, D.C. (1995). Verbal learning and memory in children with myelomeningocele. Journal of Pediatric Psychology, 20, 801-815.

Yee, S.-H., Liu, H.-L., Hou, J., Pu, Y., Fox, P.T., \& Gao, J.-H. (2000). Detection of the brain response during a cognitive task using perfusion-based event-related functional MRI. NeuroReport, 11, 2533-2536.

\section{APPENDIX A}

\section{Quantitative Segmentation Procedures}

Segmentation for all participants' brain scans was conducted at one site (Houston). The T1- and T2-weighted coronal sequences were co-aligned based on location of the external markers and validated visually using the three co-planar views. The two scan volumes were then centered within their own 256 cubic voxel bounding volume (position normalization) and each convolved with a nonlinear anisotropic diffusion filter (Gerig et al., 1992). This filter sharpens areas of high intensity gradient (along gray-white-CSF borders) and smooths regions of low-intensity gradient (inside tissue regions). The two scans were aligned a second time for the cerebellum itself by locating central cerebellar pivot points axially and coronally and then rotating and translating the volume so that the cerebellum was centered within a sagittal 
plane. A cerebellar mask was constructed from this sagitallyreformatted T2-weighted volume and the cerebellum was then "extracted" using both interactive intensity thresholding and manually drawing a curve around it on a per slice basis. The cerebellar region on each slice was then filled automatically to its drawn borders, thereby creating a volume mask.

The tissue segmentation procedure, used to estimate volumes of CSF, white and gray matter, is based on a fully automated cluster analysis using the fuzzy c-means (FCM) algorithm (Bezdek, 1981; Bezdek \& Pal, 1992; Brandt, 1995; Pao, 1989). In this procedure, cluster centroids are randomized initially and the "fuzziness" parameter is set to an intermediate level. After a first pass FCM clustering of each volume, a validity-based cluster split-and-merge (VBSM) procedure is performed on the solution (Bensaid et al., 1996). The validity measure used is the ratio of cluster compactness (intracluster variance) to intercluster distance (mean distance between centroids). This ratio is minimized iteratively by splitting each cluster in turn and merging two others. Once the VBSM step is completed, the revised solution serves as an "optimized" cluster initialization to then re-perform FCM clustering. The validity of this last run may be better or worse than the initial FCM run. The better of the two is chosen as the accepted solution. This process can be repeated until stability is achieved, usually within a few runs. Four cluster solutions were produced, two of which were gray matter sub-clusters that were merged for subsequent analysis, along with the CSF and white matter clusters. A solution volume was digitally reconstructed and compared onscreen alongside the preprocessed scan for final verification. Validity of segmentation solutions were verified by a highly experienced neuroradiologist. We have applied this procedure to brain MRI scans of typically developing children, children with hydrocephalus (Brandt et al., 1992, 1994, 1996; Fletcher et al., 1992, 1996), and specifically the cerebellums of a larger sample of children with SBM including participants in this study (Dennis et al., 2004, 2006b; Edelstein et al., 2004; Fletcher et al., 2005).

All slices for which the cerebrum or cerebellum could be visualized were segmented. For the cerebrum, three frontto-back regions within each hemisphere were measured: precallosal, pericallosal, and retrocallosal (Filipek et al., 1992). The pericallosal region subtended the coronal brain volume extending from the most anterior to the most posterior part of the corpus callosum. The precallosal region extended fully frontally from the pericallosal region whereas the retrocallosal region extended fully posteriorly from the pericallosal region.

Separate tissue volumes were obtained for the whole cerebellum, medial cerebellum, and lateral cerebellum. An algorithm was developed to estimate cerebellar volumes that would correspond to medial and lateral cerebellar regions by identifying the midsagittal cerebellum slice from the coronal series and the primary fissures to the left and right of the middle cerebellar MRI slice. In typically developing children, the vermis represented on average $11 \%$ of the total cerebellum. This estimate was used to define a medial cerebellar volume by identifying the areas $5.5 \%$ on either side of the midline, with the remainder being defined as the left or right lateral regions. The medial cerebellar volume is therefore a proxy for the vermis volume and may be subject to some error of measurement in precisely defining the vermis across individual cases.

\section{APPENDIX B}

\section{List of Words for Verb Generation Task}

$\begin{array}{lll}\text { apple } & \text { eagle } & \text { money } \\ \text { arm } & \text { farmer } & \text { paper } \\ \text { army } & \text { fish } & \text { pencil } \\ \text { ball } & \text { frog } & \text { plane } \\ \text { beach } & \text { game } & \text { road } \\ \text { bed } & \text { gate } & \text { rope } \\ \text { boat } & \text { grass } & \text { snake } \\ \text { book } & \text { gun } & \text { table } \\ \text { bottle } & \text { horn } & \text { teeth } \\ \text { bubble } & \text { knife } & \text { toy } \\ \text { cake } & \text { lake } & \text { tree } \\ \text { chair } & \text { letter } & \text { truck } \\ \text { cookie } & \text { milk } & \text { wheel } \\ \text { cup } & & \end{array}$

